\title{
Multiobjective Optimization Method for Multichannel Microwave Components of Active Phased Array Antenna
}

\author{
Lu Wang, ${ }^{1}$ Zhihai Wang, ${ }^{1}$ Congsi Wang, ${ }^{2}$ Guozhou Li, ${ }^{2}$ and Lei Yin ${ }^{2}$ \\ ${ }^{1}$ China Electronics Technology Group Corporation No. 38 Research Institute, Hefei 230088, China \\ ${ }^{2}$ Key Laboratory of Electronic Equipment Structure Design, Ministry of Education, Xidian University, Xian 710071, China \\ Correspondence should be addressed to Congsi Wang; congsiwang@163.com
}

Received 18 November 2015; Accepted 17 March 2016

Academic Editor: Antonina Pirrotta

Copyright (c) 2016 Lu Wang et al. This is an open access article distributed under the Creative Commons Attribution License, which permits unrestricted use, distribution, and reproduction in any medium, provided the original work is properly cited.

\begin{abstract}
Multichannel microwave components are widely used and the active phased array antenna is a typical representative. The high power generated from T/R modules in active phased array antenna (APAA) leads to the degradation of its electrical performances, which seriously restricts the development of high-performance APAA. Therefore, to meet the demand of thermal design for APAA, a multiobjective optimization design model of cold plate is proposed. Furthermore, in order to achieve temperature uniformity and case temperature restrictions of APAA simultaneously, optimization model of channel structure is developed. Besides, an airborne active phased array antenna was tested as an example to verify the validity of the optimization model. The valuable results provide important reference for engineers to enhance thermal design technology of antennas.
\end{abstract}

\section{Introduction}

Multichannel digital microwave components are widely used in many airborne systems. Since the airborne equipment usually works in a harsh environment, the structural size and weight of the microwave component with vibration resistance and temperature uniformity should be treated carefully. Active phased array antenna (APAA), which is made up of thousands of T/R components, is typical of the multichannel microwave component application. Because of high reliability, multifunction, far detection, tracking capability, and good stealth properties, APAA has been widely used in various radar systems [1-3]. The APAA contains large numbers of heating devices, including the temperaturesensitive Transmitter and Receiver (T/R) components. The control accuracy of array phase is severely affected by the nonuniform distribution of temperature. Meanwhile, the radiation pattern of the element is greatly changed due to the thermal deformation. Then, the performance of the antenna would degrade from bad to worse [4-6]. Therefore, a high efficiency cooling system of APAA is required.

At present, the efficiency of the power amplifier in the many kinds of T/R module is always maintained at $30 \%$, and the remaining $70 \%$ radiation energy of the power amplifier is directly converted into heat [7]. Therefore, Scott, the closed air cycle cooling and liquid cooling (water/glycol as coolant) combination of Sampson MFR radar heat dissipation design, has effective dissipation of about $30 \mathrm{Kw} / \mathrm{m}^{2}$ heat level, which can ensure the array surface temperature to maintain reliable operation range [8]. USA AN/FPS-115 "PAVE PAWS" Radar uses liquid cooling and air cooling mode of combining. When the radar works under high temperature environment, the cooling system operates in the main cooling way: liquid cooling; when fault occurs in the primary cooling system, it starts the auxiliary cooling system: air cooling [9]. Zhang et al. proposed a method for active phased array antenna with baffles S-type cold to avoid heat concentration while increasing the heat transfer area [10], but not for the cold plate structure optimization. The microchannel heat sink of air cooling is used in certain avionics, and the operation performance of the microchannel heat sink is studied [11]. But the influence of the rib height, rib width, and other structures on the thermal performance of the microchannel heat sink is not analyzed. Agrawal et al. studied the simulation of the heat sink and the thermal field distribution of the shipboard active phased array antenna [12], but there is no subsequent optimization analysis carried out to enhance the cooling performance for airborne antenna. 


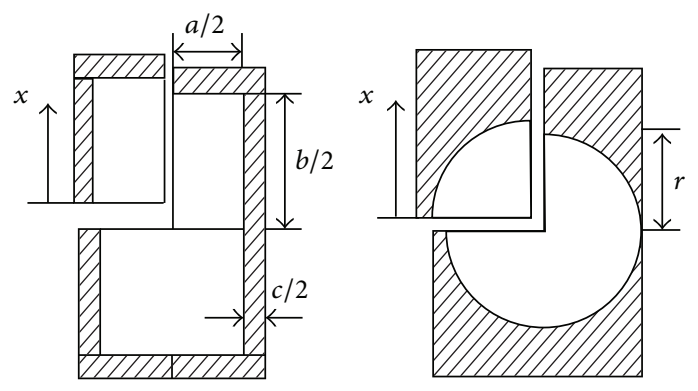

FIGURE 1: Rectangular channel and circular flow channel.

In this paper, the cold plate cooling system with multiobjective optimization design is discussed to meet the antenna surface temperature uniformity, the electronic device case temperature limit, and other requirements for APAA. Taking an active phased array antenna as an example, cold plate cooling performance verified the validity of the optimization model. The results and conclusions can provide some theoretical guidance to electronic equipment thermal design.

\section{Cold Plate Structural Optimization of APAA}

2.1. Optimization Model. Active phased array antenna cooling is mainly through cold plate, for its high efficiency and easy maintenance in cooling the APAA plates. Generally, the cold plate structure is a single plate-fin heat exchanger with heating elements mounted on the surface or bottom of the cold plate. As a result, the variables are geometry and topology shape of the flow channel in terms of the design of the structure of cold plate. The variables are $\beta=\left(\beta_{1}, \beta_{2}, \ldots\right.$, $\left.\beta_{i}, \ldots\right), i=1,2,3, \ldots$.

The optimization of the cold plate is divided into two: first the design variables meeting the basic requirement of the thermal design of APAA and second the design variables meeting the requirement of thermal design of APAA. Thereby, it can make the contribution of the design variables to the thermal design clear. Besides, it has the benefit of highlighting the goal of design, while reducing the workload. The main objectives of APAA cold plate cooling structure are as follows.

(1) The Limitations of the Maximum Temperature of $T / R$ Module. T/R module is the core in the realization of APAA's electrical properties and the power amplifier (HPA) is the main heating device. To ensure the reliability of the T/R module, the junction temperature of HPA should be below the permissible value. Currently, the main basic material for HPA device in T/R module is gallium arsenide ( $\mathrm{GaAs}$ ), the junction temperature of which should not be above $150^{\circ} \mathrm{C}$. The case temperature of HPA device is $70^{\circ} \mathrm{C}$, calculated by the equation $t_{s}=t_{j \max }-R_{j c} P_{\max }$, taking into consideration the inner resistance $R_{j c}\left({ }^{\circ} \mathrm{C} / \mathrm{W}\right)$ and the maximum power consumption $P_{\max }(\mathrm{W})$ as the thermal parameters of GaAs.

(2) The Temperature Uniformity Requirement of APAA Plate. In order to guarantee the stability of the electric properties of APAA array, the T/R module should have strict phase control accuracy, and the average temperature of every two $\mathrm{T} / \mathrm{R}$ modules should not exceed $10^{\circ} \mathrm{C}$.

(3) APAA Cold Convective Heat Transfer Performance. The cooling capacity of the cooling plate is directly related to the heat transfer capability of the cooling fluid in the flow channel. The convective heat transfer coefficient $\left(\mathrm{W} / \mathrm{m}^{2 \circ} \mathrm{C}\right)$ is characterized by the Newton cooling formula:

$$
\begin{array}{r}
h A\left(t_{w}-t_{f}\right)=q_{m} C_{p}\left(t_{f}^{\prime \prime}-t_{f}^{\prime}\right), \\
h=\frac{q_{m} C_{p}\left(t_{f}^{\prime \prime}-t_{f}^{\prime}\right)}{A\left(t_{w}-t_{f}\right)},
\end{array}
$$

where $t_{w}\left({ }^{\circ} \mathrm{C}\right)$ is the solid temperature; $t_{f}^{\prime}\left({ }^{\circ} \mathrm{C}\right)$ is the fluid inlet temperature; $t_{f}^{\prime \prime}\left({ }^{\circ} \mathrm{C}\right)$ is the fluid outlet temperature.

(4) The Thermal Performance of APAA Cold Plate. The temperature of the heat source transfers through heat conduction, due to the fact that APAA cold plate is in direct contact with the heat source. Therefore, the heat conductivity of the cold plate should also be included as important parameters in measuring its cooling capacity. Figure 1 is the analysis of the heat conductivity of cold plate in the form of rectangular channel and circular flow channel.

For rectangular channel, according to Fourier's law, the following can be obtained:

$$
\begin{aligned}
& \frac{Q}{b / 2} x=-\lambda \cdot \frac{c}{2} L \cdot \frac{d T}{d x}, \\
& \Delta T_{\text {rec }}^{\prime}=-\int_{0}^{b / 2} \frac{4 Q}{\lambda b c L} x d x=-\frac{Q}{\lambda L} \frac{b}{2 c} .
\end{aligned}
$$

For circular channel cold plate, the temperature distribution of the rib plate is simplified to one-dimensional heat conduction, according to the Fourier law:

$$
\begin{aligned}
\frac{Q}{r} x & =-\lambda \cdot\left(w-\sqrt{r^{2}-x^{2}}\right) L \cdot \frac{d T}{d x}, \\
\Delta T_{\text {cir }}^{\prime} & =-\int_{0}^{r} \frac{Q}{r \lambda L} \frac{1}{w-\sqrt{r^{2}-x^{2}}} x d x \\
& =-\frac{Q}{\lambda L}\left(w \ln \frac{w}{w-r}-r\right),
\end{aligned}
$$



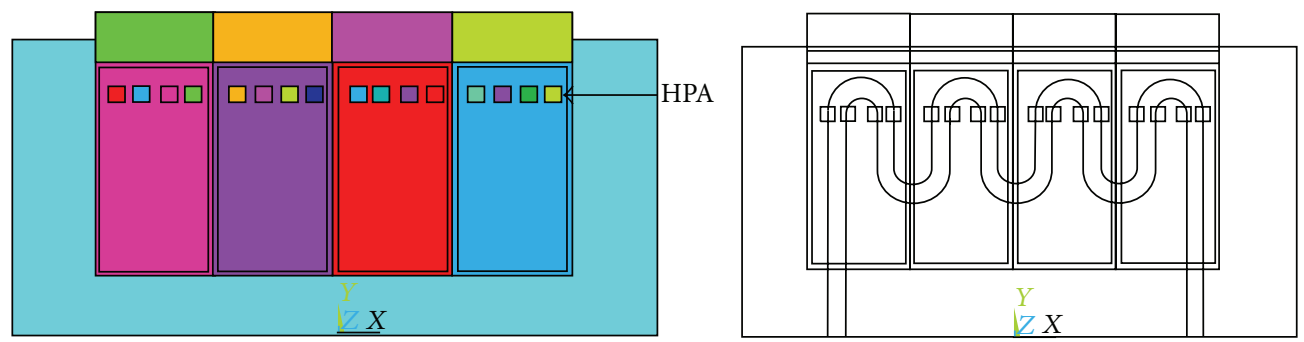

Figure 2: Antenna line array model and flow channel model.

where $Q$ is the total heat exchange rate of the half rib, $L$ is the length of the flow channel, $\lambda$ is the heat conduction coefficient, and $\Delta T^{\prime}$ is the semirib high thermal temperature difference.

Contrasting Rectangular Channel. It is formulated as follows:

$$
\begin{gathered}
w=\frac{a+c}{2}, \\
r=\frac{2 a b}{a+b} .
\end{gathered}
$$

The thermal conductivity of cold plate is related to the flow height, the thickness, and the width of the rib. To sum up, the thermal design requirements of APAA are combined with the linear weighting method and the objective programming method. The structure optimization model of APAA cold plate is established:

Find: $\beta=\left(\beta_{1}, \beta_{2}, \beta_{3}, \ldots, \beta_{i}, \ldots\right), \quad i=1,2,3, \ldots$

min: $F(\beta)$

$$
\begin{gathered}
=\alpha_{1}\left(\frac{T_{a \max }(\beta)}{T_{a \_\max }^{*}(\beta)}\right)^{2}+\alpha_{2}\left(\frac{\Delta T_{a}(\beta)}{\Delta T_{a}^{*}(\beta)}\right)^{2} \\
+\alpha_{3}\left(\frac{h(\beta)}{h^{*}(\beta)}\right)^{-2}+\alpha_{4}\left(\frac{\Delta T^{\prime}(\beta)}{\Delta T^{\prime *}(\beta)}\right)^{2}
\end{gathered}
$$

$$
\begin{array}{ll}
\text { s.t.: } & T_{a \_ \text {max }}(\beta) \leq T_{a \_ \text {max }}^{p} \\
& \Delta T_{a}(\beta) \leq \Delta T_{a}^{p} \\
& \Delta P \leq \Delta P^{p} \\
& \beta_{i \min } \leq \beta_{i} \leq \beta_{i \max } \quad i=1,2,3 \ldots,
\end{array}
$$

where $T_{a-\max }^{p}$ is the maximum temperature allowed for antenna array, $\Delta T_{a}^{p}$ is the temperature difference allowed for antenna array, $\Delta P^{P}$ is the allowed pressure drop,

$$
\begin{aligned}
\sum_{i=1}^{4} \alpha_{i} & =1, \\
T_{a \_ \text {max }}^{*}(\beta) & =\min T_{a \_ \text {max }}(\beta), \\
\Delta T_{a}^{*}(\beta) & =\min \Delta T_{a}(\beta), \\
h^{*}(\beta) & =\max h(\beta) .
\end{aligned}
$$

2.2. Optimization Method. ISIGHT software is used to achieve the APAA cold plate heat dissipation model, that is, the establishment of multipurpose optimization mathematical model through the integration of software by the integration of CAD and CAE software through ISIGHT. ISIGHT has integrated a variety of optimization methods, including (1) the method of numerical optimization, which is suitable for the design space as a single peak value, when the space is a convex and continuous space; (2) the method of search optimization exploring, which can avoid the local optimal solution, while searching for the global optimal value in the whole design space; (3) the method of expert system optimization, which can directly affect the optimization solution of the parameters [13]. The classification and characteristics of the three methods are shown in Table 1.

\section{Simulation Results and Discussion}

$\mathrm{X}$-band airborne active phased array antenna is composed of radiating element, $T / R$ module, cold plate antenna, and antenna frame, the antenna radiation using cold plate cooling mode. A linear array model is selected as the example for the airborne active phased array antenna. As shown in Figure 2, an S-type flow channel is applied to the cold plate of the linear array model.

Using ANSYS/FLOTRAN for linear array model for thermal analysis, linear array structure finite element model and flow channel finite element model are shown in Figure 3.

Through the analysis, the internal pressure drop distribution and flow velocity distribution of the outlet channel are shown in Figure 4. It can be seen that the pressure drop is $7570 \mathrm{~Pa}$, the maximum flow rate is $3.29 \mathrm{~m} / \mathrm{s}$, and the range of flow velocity is located at the corner of $\mathrm{S}$. The increase of flow rate can accelerate the flow of liquid from the laminar state into the turbulent state. The convective heat transfer performance of the liquid can be improved, and the temperature field distribution of the antenna is calculated. The results are shown in Figures 5 and 6.

From the result obtained, the HPA chip maximum case temperature is $77.85^{\circ} \mathrm{C}$, with chip temperature range at about $15^{\circ} \mathrm{C}$, and the temperature distribution does not meet the HPA chip shell of the highest temperature of $70^{\circ} \mathrm{C}$ requirements and chip temperature requirements. In addition, from Figure 6, the temperature difference between the four groups of $\mathrm{T} / \mathrm{R}$ components is greater than $10^{\circ} \mathrm{C}$, so the cooling effect of the runner model does not meet the requirements of APAA 

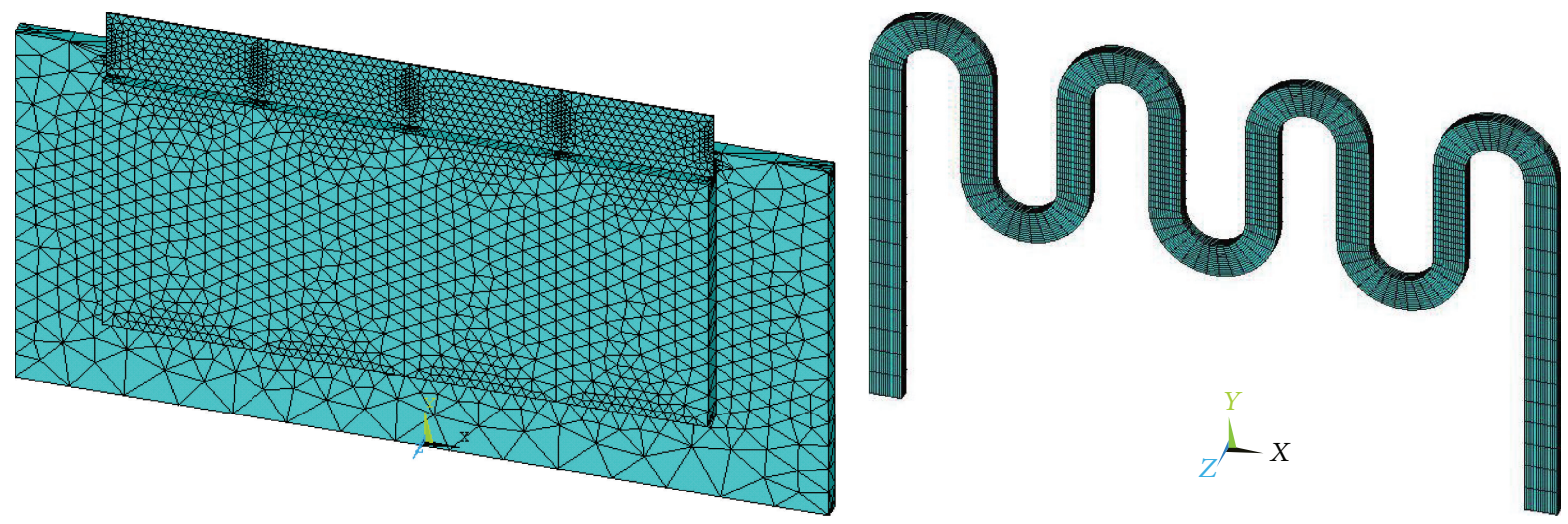

FIGURE 3: Finite element model of linear array antenna and channel structure.
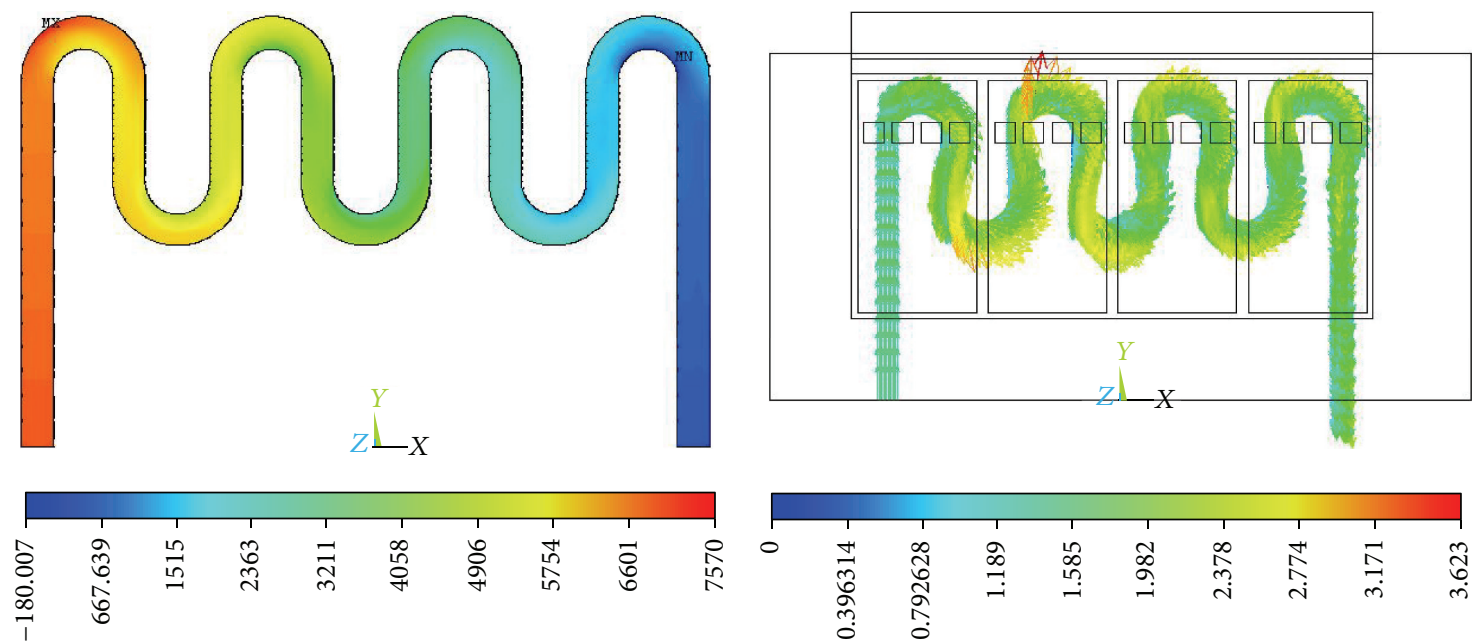

FIGURE 4: Flow channel pressure drop distribution and velocity vector diagram.
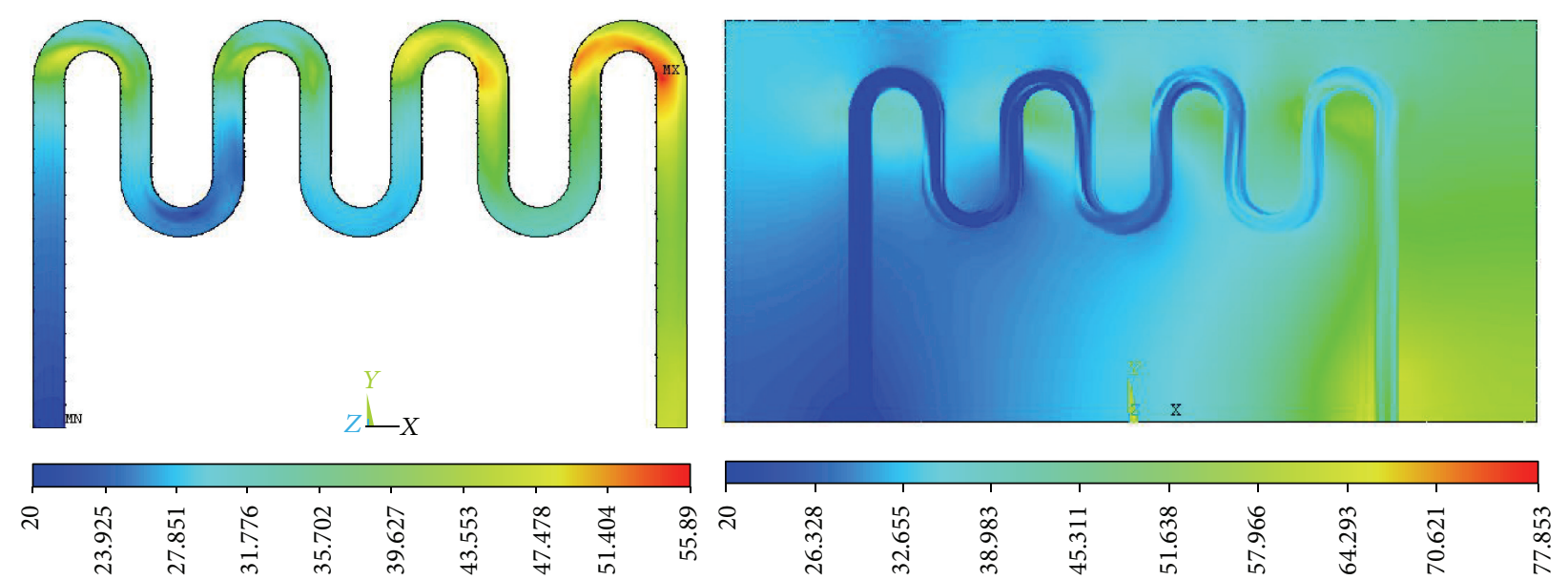

FIGURE 5: Temperature distribution of flow channel. 
TABLE 1: ISIGHT optimization algorithm.

\begin{tabular}{|c|c|c|}
\hline Classification & Name & Characteristic \\
\hline \multirow{9}{*}{$\begin{array}{l}\text { Numerical optimization } \\
\text { method }\end{array}$} & Exterior point (EP) penalty function & $\begin{array}{l}\text { (1) Finding the real target value in the case of a } \\
\text { minimum } \\
\text { (2) Penalty function: improving reliability }\end{array}$ \\
\hline & $\begin{array}{l}\text { Generalized reduced gradient } \\
\text { (LSGRG2) }\end{array}$ & $\begin{array}{l}\text { (1) A large number of design variables }(>20) \text { and } \\
\text { constraints }(>2000) \\
\text { (2) Optimization equation based on the Kutta condition }\end{array}$ \\
\hline & $\begin{array}{l}\text { Generalized Hooke's law direct } \\
\text { search (DHS) }\end{array}$ & $\begin{array}{c}\text { Local optimization, not requiring the objective function } \\
\text { to be continuous } \\
\text { (2) Providing convergence coefficient, ensuring } \\
\text { convergence }\end{array}$ \\
\hline & Feasible direction (CONMIN) & $\begin{array}{l}\text { (1) Reducing the objective function value to maintain } \\
\text { the feasible solution } \\
\text { (2) Achieving the target value quickly }\end{array}$ \\
\hline & $\begin{array}{l}\text { Mixed integer optimization } \\
\text { (MOST) }\end{array}$ & $\begin{array}{l}\text { (1) Designing a continuous variable } \\
\text { (2) The handle mixed or unmixed real, integer, and } \\
\text { discrete variable }\end{array}$ \\
\hline & Sequential Linear Programming & $\begin{array}{c}\text { Being easy to achieve, being commonly used in } \\
\text { engineering }\end{array}$ \\
\hline & Sequential Quadratic Programming & Gradient cannot handle user-supplied data \\
\hline & $\begin{array}{c}\text { Sequential Quadratic Programming } \\
\text { (NLPQ) }\end{array}$ & $\begin{array}{l}\text { (1) Assuming that the target function is continuously } \\
\text { differentiable } \\
\text { (2) Adding the linear search which improves the } \\
\text { stability of the algorithm }\end{array}$ \\
\hline & Successive approximation & The nonlinear problem as a linear problem to deal with \\
\hline \multirow{2}{*}{$\begin{array}{l}\text { Exploration } \\
\text { optimization }\end{array}$} & $\begin{array}{l}\text { Multi-island genetic algorithm } \\
\text { (MIGA) }\end{array}$ & $\begin{array}{l}\text { (1) Handling equality or inequality constraints } \\
\text { (2) Starting until you can get a good target } \\
\text { (3) From the point of looking for a series of designs } \\
\text { rather than from a single point }\end{array}$ \\
\hline & $\begin{array}{l}\text { Adaptive simulated annealing } \\
\text { (ASA) algorithm }\end{array}$ & $\begin{array}{c}\text { (1) Solving highly nonlinear optimization problem, } \\
\text { identifying the different local optima } \\
\text { (2) Being able to obtain the optimal solution with the } \\
\text { minimum cost }\end{array}$ \\
\hline $\begin{array}{l}\text { Expert system } \\
\text { optimization }\end{array}$ & $\begin{array}{l}\text { Directed heuristic search (DHS) } \\
\text { algorithm }\end{array}$ & $\begin{array}{l}\text { (1) High speed nonlinear problem } \\
\text { (2) Focusing on the parameters that can directly affect } \\
\text { the optimization solution }\end{array}$ \\
\hline
\end{tabular}

TABLE 2: Optimized design results contrast with the initial design.

\begin{tabular}{lccccccc}
\hline \multirow{2}{*}{ Design category } & \multicolumn{3}{c}{ Design variable (unit: mm) } & \multicolumn{3}{c}{ Objective function } \\
& $\beta_{1}$ & $\beta_{2}$ & $\beta_{3}$ & $\beta_{4}$ & $\beta_{5}$ & $\beta_{6}$ & $F(\beta)$ \\
\hline Initial design & -120 & 130 & 10 & 11 & 30 & 11 & 0.98 \\
Optimization design & -123.5 & 126.1 & 11.2 & 10.4 & 37.8 & 12.1 & 0.86 \\
\hline
\end{tabular}

thermal design, the flow structure is optimized, and the shape of the $S$ channel is changed (shown in Figure 7).

According to the optimization of the APAA cold plate flow channel in Section 2.1, the structure of the flow channel is optimized. And the design variables mainly include the position of the cooling plate $\beta_{1}: x$, the length of the cooling plate $\beta_{2}$ : length, the radius of the curve in the channel $\beta_{3}: R_{1}$, inner radius of lower turn $\beta_{4}: r_{1}$, distance between corners $\beta_{5}$ : length, and the inlet width of the channel $\beta_{6}$, considering the pressure strength of cold plate, so the height of the flow channel is fixed. In the ISIGHT optimization process, the NLPQL method is used to solve the optimization problem, and the accuracy is $10 e-3$, and the computer configuration was Pentium ${ }^{\circledR}$ Dual-Core CPU E6600 at $3.06 \mathrm{GHz}$ and $3.07 \mathrm{GHz}$, with $2 \mathrm{G}$ of RAM, the calculated use time is $2 \mathrm{~h}$ and $26 \mathrm{~min}$.

Optimizations of APAA cold plate cooling design parameters and initial design parameters were compared, as shown in Table 2; it can be seen that, after optimization, optimization objective function improved by $12 \%$. And through simulation analysis of temperature field, temperature of the linear array antenna $T / R$ module is reduced to $11^{\circ} \mathrm{C}$, and the maximum case temperature of the HPA chip is reduced to $72^{\circ} \mathrm{C}$, in contrast to the initial flow design, which basically meets the thermal design requirements of APAA cold plate cooling. 

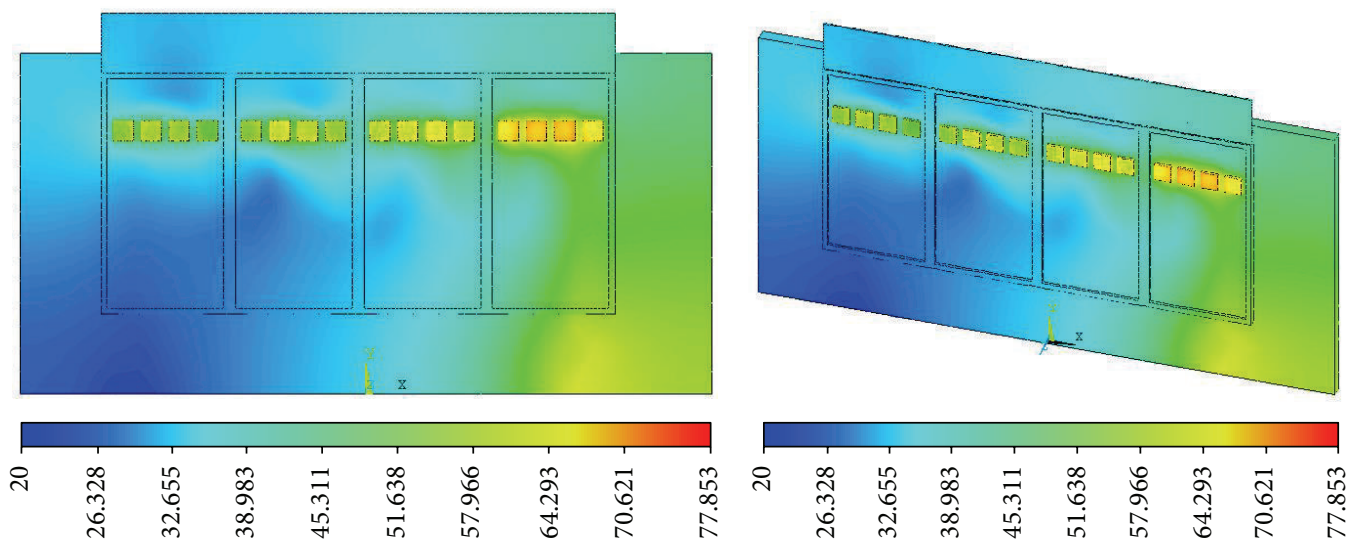

FIGURE 6: Temperature distribution of linear array.

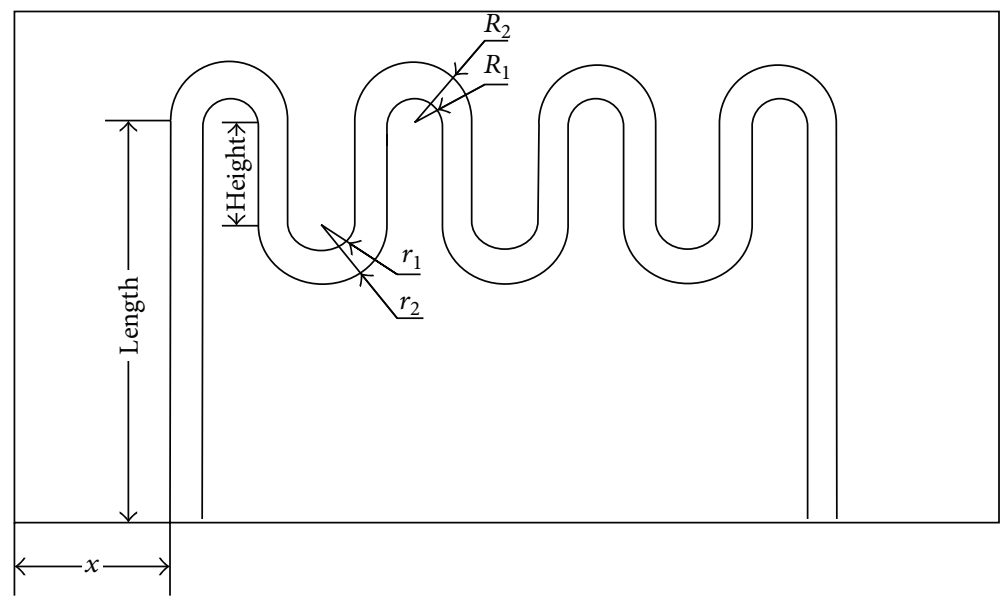

FIGURE 7: Flow structure parameter diagram.

\section{Conclusions}

The optimization analysis of APAA cool plate was made in detail. To meet the high cooling property, the size of the cold plate structure is selected as the design variable; to decrease antenna array maximum temperature, temperature uniformity is also chosen as the constraint condition; to improve antenna design combined with cold plate thermal conductivity and heat transfer performance, the optimization model is developed ultimately. The application of this optimization model to the X-band airborne active phased array antenna is made with many valuable results. The maximum temperature of HPA chip is reduced from $77.85^{\circ} \mathrm{C}$ to $72^{\circ} \mathrm{C}$, and the temperature difference among the $\mathrm{T} / \mathrm{R}$ modules is also decreased from $15^{\circ} \mathrm{C}$ to $11^{\circ} \mathrm{C}$. Therefore, the structure optimization of cold plate can effectively improve the cooling performance, which provides a theoretical reference for improving the performance of microwave components and also provides a reference for the thermal design of electronic equipment.

\section{Competing Interests}

The authors declare that they have no competing interests.

\section{Acknowledgments}

This work was supported by the National Natural Science Foundation of China under Grants nos. 51522507 and 51475349, the National 973 Program under Grant no. 2015CB857100, Research Fund for the Doctoral Program of Higher Education of China under Grant no. 20120203110012, the National 111 Project under Grant no. B14042, and the Fundamental Research Funds for the Central Universities under Grants nos. SPSZ011401 and 7214479606.

\section{References}

[1] C. Luison, A. Landini, P. Angeletti et al., "Aperiodic arrays for spaceborne SAR applications," IEEE Transactions on Antennas and Propagation, vol. 60, no. 5, pp. 2285-2294, 2012.

[2] T. Lambard, O. Lafond, M. Himdi, H. Jeuland, S. Bolioli, and L. Le Coq, "Ka-band phased array antenna for high-data-rate SATCOM," IEEE Antennas and Wireless Propagation Letters, vol. 11, pp. 256-259, 2012.

[3] C. S. Wang, B. Y. Duan, F. S. Zhang, and M. B. Zhu, "Coupled structural-electromagnetic-thermal modelling and analysis of active phased array antennas," IET Microwaves, 
Antennas and Propagation, vol. 4, no. 2, Article ID IMAPCH000004000002000247000001, pp. 247-257, 2010.

[4] P. Schuh, H. Sledzik, R. Reber et al., "T/R-module technologies today and future trends," in Proceedings of the IEEE European Microwave Conference, pp. 1540-1543, Paris, France, September 2010.

[5] C. S. Wang, H. Bao, Y. Y. Qiu, and G. D. Chen, "Mechanical thermal coupling optimization analysis of spaceborne intelligent antenna structure," Journal of Radio Science, vol. 23, no. 5, pp. 991-996, 2008 (Chinese).

[6] K. Kawakami, H. Nakamizo, K. Tajima et al., "A C-Ku-band RF module transmitter including an RF signal generator for a flexible phased-array system," IEEE Transactions on Microwave Theory and Techniques, vol. 61, no. 8, pp. 3052-3059, 2013.

[7] S. V. Garimella, A. S. Fleischer, J. Y. Murthy et al., "Thermal challenges in next-generation electronic systems," IEEE Transactions on Components and Packaging Technologies, vol. 31, no. 4, pp. 801-815, 2008.

[8] M. Scott, "SAMPSON MFR active phased array antenna," in Proceedings of the IEEE International Symposium on Phased Array Systems and Technology, pp. 119-123, IEEE, Boston, Mass, USA, October 2003.

[9] D. J. Hoft, "Solid state transmit/receive module for the PAVE PAWS (AN/FPS-115) phased array radar," in Proceedings of the IEEE-MTT-S International Microwave Symposium, pp. 239-241, Ottawa, Canada, June 1978.

[10] Y. P. Zhang, X. L. Yu, Q. K. Feng, and R. T. Zhang, “Thermal performance study of integrated cold plate with power module," Applied Thermal Engineering, vol. 29, no. 17-18, pp. 3568-3573, 2009.

[11] F. P. Incropera, Liquid Cooling of Electronic Devices by SinglePhase Convection, Wiley-Interscience, New York, NY, USA, 1999.

[12] A. K. Agrawal, B. A. Kopp, M. H. Luesse, and K. W. O’Haver, "Active phased array antenna development for modern shipboard radar systems," Johns Hopkins APL Technical Digest, vol. 22, no. 4, pp. 600-613, 2001.

[13] P. N. Koch, J. P. Evans, and D. Powell, "Interdigitation for effective design space exploration using iSIGHT," Structural and Multidisciplinary Optimization, vol. 23, no. 2, pp. 111-126, 2002. 


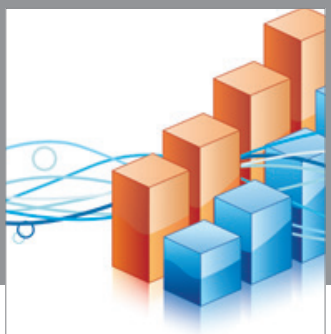

Advances in

Operations Research

vatem alat4

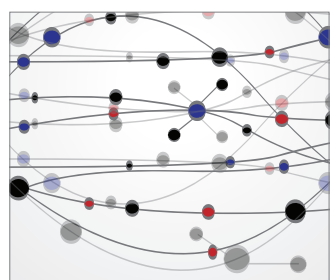

\section{The Scientific} World Journal
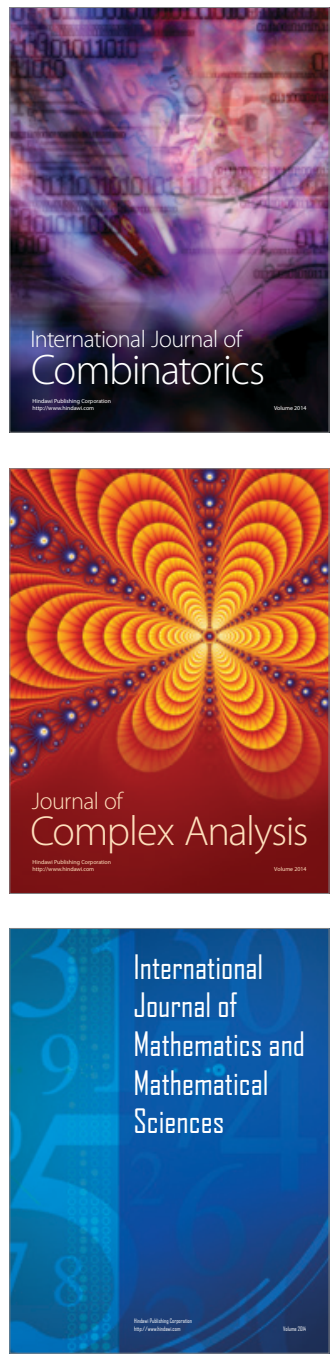
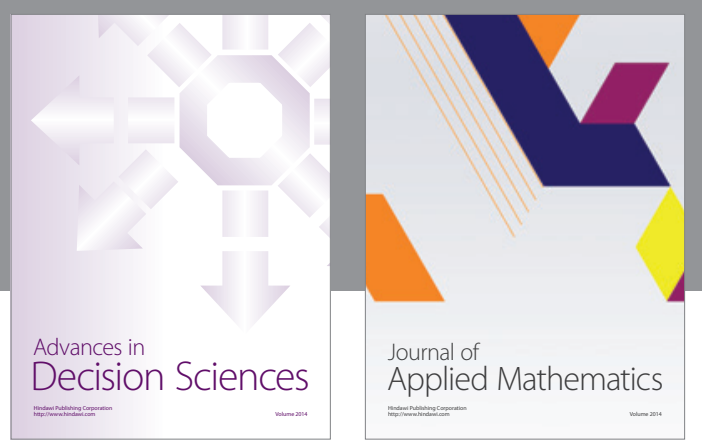

Algebra

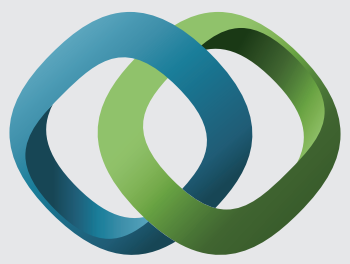

\section{Hindawi}

Submit your manuscripts at

http://www.hindawi.com
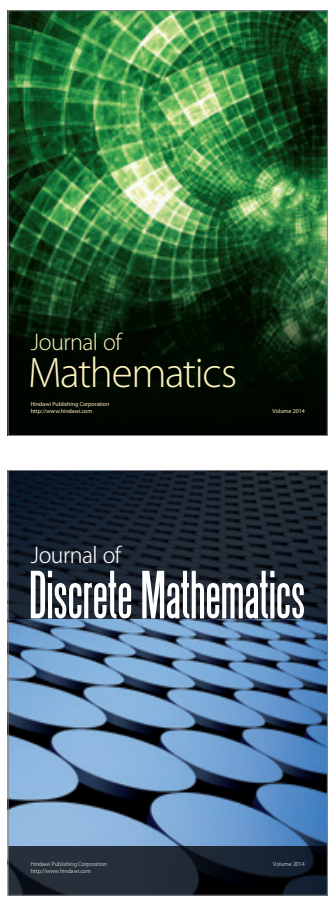

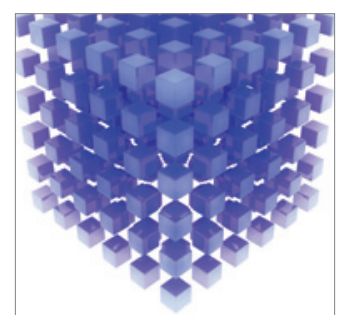

Mathematical Problems in Engineering
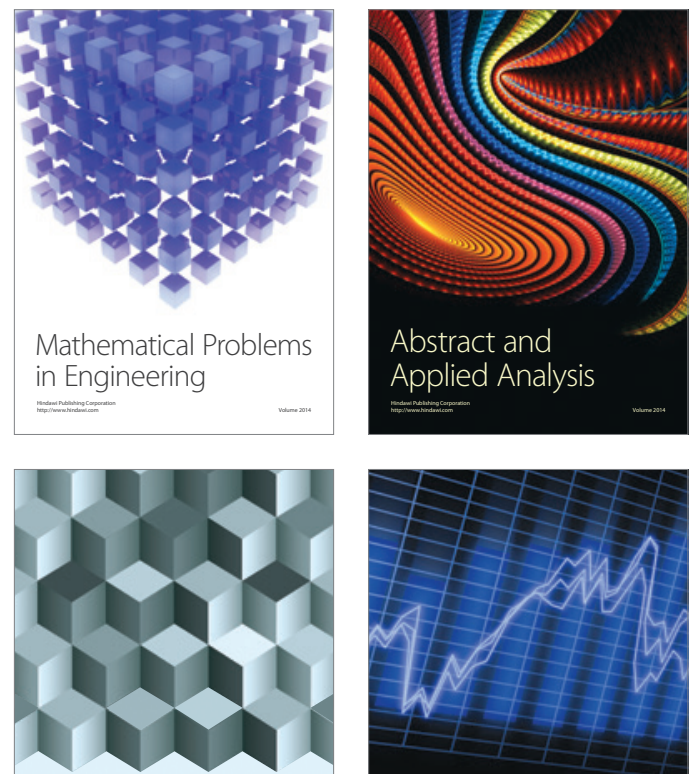

Journal of

Function Spaces

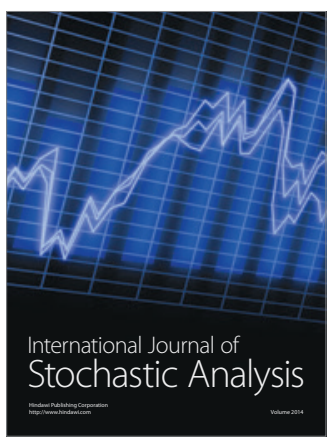

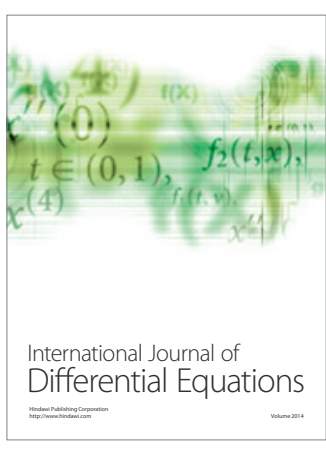
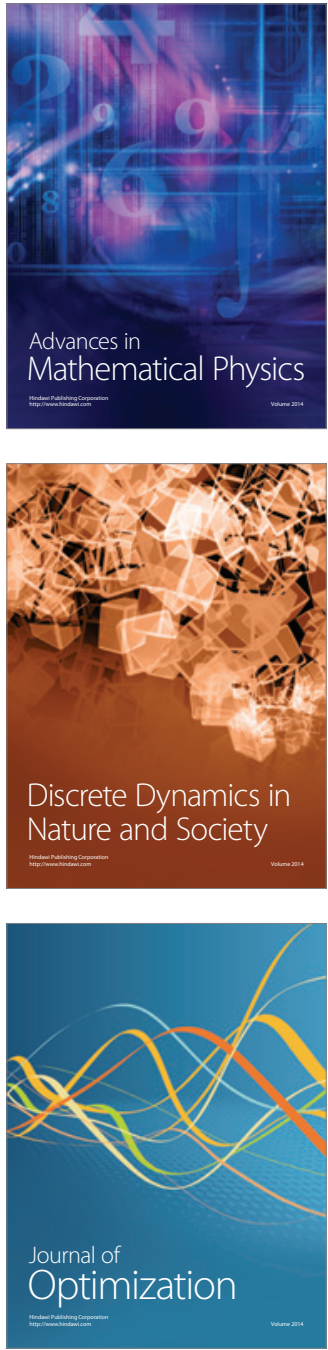